\title{
États-Unis : dernière réforme en éducation
}

Marion Latour

\section{OpenEdition}

\section{Journals}

Édition électronique

URL : https://journals.openedition.org/ries/1785

DOI : $10.4000 /$ ries. 1785

ISSN : 2261-4265

\section{Éditeur}

France Education international

\section{Édition imprimée}

Date de publication : 1 septembre 2002

Pagination : 10-12

ISBN : 978-285420-554-1

ISSN : 1254-4590

\section{Référence électronique}

Marion Latour, «États-Unis : dernière réforme en éducation », Revue internationale d'éducation de Sèvres [En ligne], 30 | septembre 2002, mis en ligne le 23 novembre 2011, consulté le 06 juillet 2021. URL: http://journals.openedition.org/ries/1785; DOI : https://doi.org/10.4000/ries.1785

Ce document a été généré automatiquement le 6 juillet 2021

(c) Tous droits réservés 


\title{
États-Unis : dernière réforme en éducation
}

\author{
Marion Latour
}

George W. Bush a tenu sa promesse de faire de l'éducation la pierre angulaire de son action gouvernementale, en signant le 8 janvier 2002 le No Child Left Behind Act, (NCLB Act). Approuvée à une très forte majorité par le Congrès, la loi vise à améliorer le niveau général de l'enseignement primaire et secondaire, tout en ne laissant « aucun élève à la traîne ». Le NCLB Act s'inscrit dans le prolongement de la loi de 1994, ellemême reconduction de l'Elementary and Secondary Education Act ${ }^{1}$, ESEA, signé en 1965.

\section{Le contenu de la réforme}

2 Le NCLB Act préconise notamment l'obligation de résultats, une plus grande autonomie dans la gestion locale des financements fédéraux et un recentrage des ressources sur les programmes performants. Il renforce le choix laissé aux parents de l'établissement accueillant leurs enfants.

3 Entre 8 et 13 ans, les enfants devront passer des tests annuels de mathématiques et de lecture. Liberté sera laissée aux États du choix des tests, ces derniers devant être alignés sur les critères respectifs des États. Écoles, districts scolaires et États devront attester de résultats suffisants par rapport à une moyenne fédérale et seront tenus chaque année de prouver les progrès des enfants sous leur responsabilité ${ }^{2}$. Les trois premières années, des résultats insuffisants seront compensés par une aide financière permettant de mieux suivre les enfants en difficulté, mais après quatre années consécutives, des actions correctives seront prises, qui peuvent aller jusqu'à un changement structurel de l'établissement.

4 L'obligation de progrès porte également sur le corps enseignant; d'ici à la fin de l'année scolaire 2005-2006, les États devront attester du « haut niveau de qualification des professeurs $»^{3}$. 
5 En contrepartie de ces comptes à rendre, les États et les agences locales d'éducation jouiront d'une plus grande souplesse dans l'usage des fonds fédéraux et verront les démarches administratives se simplifier. Par souci d'un meilleur rendement, les programmes fédéraux seront en nombre plus restreint, passant de 55 à 45 , et porteront prioritairement sur la formation des enseignants et les initiatives en faveur des plus défavorisés.

6 Dès la prochaine rentrée scolaire, les parents auront le droit de changer leurs enfants d'établissement, si celui qu'ils fréquentent est explicitement identifié comme ayant des résultats insuffisants. L'élève pourra être accueilli dans une école publique ou une charter school 4 , type d'école indépendante sous contrat dont le NCLB Act souhaite promouvoir la création.

\section{Les réactions}

7 La nouvelle loi a reçu un accueil globalement favorable des gouverneurs des États et des cadres éducatifs, notamment parce qu'elle est synonyme de financements accrus. Présenté le 4 février dernier par la Maison Blanche, le budget prévisionnel américain 2003 prévoit 56,5 milliards de dollars ${ }^{5}$ pour le département de l'éducation, dont 11,4 milliards affectés aux écoles enregistrant les plus faibles résultats.

8 Néanmoins, si la finalité de la réforme reçoit l'approbation d'une majorité des acteurs de l'enseignement, la réalisation concrète des mesures suscite inquiétude et scepticisme, à commencer par les tests et « standards ». Education $W_{e e k^{6}}$ a enquêté sur les pratiques d'évaluation actuellement en cours dans les cinquante États et le District de Columbia; seuls neuf États utilisent des tests conformes aux critères précis de la nouvelle loi .

9 Le haut niveau de qualification requis pour les enseignants, s'il est plébiscité par tous, reste un objectif très difficile à atteindre dans la pratique. Certains États, tels que la Californie et le Mississipi, connaissent déjà une pénurie d'enseignants. En outre, les responsables de formation des enseignants redoutent qu'il y ait, pour satisfaire à ces critères ambitieux, un nivellement par le bas des examens et des tests d'habilitation des enseignants.

10 Le choix de l'établissement par les parents promet lui aussi d'être difficile à appliquer dans les régions rurales, qui comptent un nombre élevé de districts à école unique et où les distances pouvant séparer deux établissements sont grandes. Au Texas et au Kentucky, rares ont été les parents à avoir exercé ce droit.

11 Par ailleurs, la responsabilisation financière, avec l'obligation de résultats, était déjà inscrite dans la loi de 1994. Or seuls vingt-huit États avaient pu s'aligner en trois ans sur les recommandations fédérales ; le ministère quant à lui n'a jamais examiné les projets établis par les États, de mise en conformité de leurs engagements avec les termes de la loi.

12 L'enlisement des dernières réformes fédérales en éducation peut s'expliquer en partie par la tradition américaine d'autonomie et de liberté des États. Mais ceux-ci semblent aujourd'hui davantage favorables à la nouvelle réforme. L'idée d'un partenariat indispensable entre le niveau fédéral et les instances sur le terrain fait son chemin. En témoigne la rencontre officielle qui a rassemblé, début janvier 2002 à Washington, des 
chefs d'établissement de près de trente États et des hauts fonctionnaires du département fédéral.

\section{NOTES}

1. Loi sur l'enseignement élémentaire et secondaire, qui met la priorité sur les enfants issus de milieux économiquement très défavorisés et ceux présentant des risques d'échec scolaire. Depuis sa promulgation, le gouvernement fédéral a dépensé près de 200 milliards de dollars pour améliorer le niveau des écoles publiques. Ce chiffre est avancé par le département fédéral de l'Éducation, dans son résumé daté du 7 janvier 2002 du No Child Behind Act, consultable à l'adresse http://www.ed.gov/offices/OESE/esea/exec-summ.html/.

2. Il s'agit de l'obligation d'adequate yearly progress (AYP) (« progrès annuels suffisants »).

3. Traduction à partir des textes consultés où l'expression highly qualified apparaît entre guillemets.

4. Les charter schools sont souvent adaptées aux besoins de la communauté. Elles sont régies par un contrat passé entre personnes privées et autorités scolaires, qu'elles soient locales, régionales ou à l'échelle des États, et reçoivent des financements publics.

5. Soit 2,65\% du budget prévisionnel global pour 2003.

6. Education Week, hebdomadaire électronique de l'association spécialisée en éducation Editorial Projects in Education, édite depuis 1997 un rapport annuel sur les conditions de l'enseignement public, appelé Quality Counts.

7. « Testing systems in most states not ESEA ready » in Education Week, 9 janvier 2002.

\section{INDEX}

Mots-clés : réforme de l'enseignement, système éducatif

Index géographique : États-Unis

\section{AUTEUR}

\section{MARION LATOUR}

Documentaliste au CIEP. [latour@ciep.fr] 